\title{
Influences of temperature and precipitation on soil moisture in Anuradhapura District
}

\author{
Udeni P. Nawagamuwa ${ }^{1 * \dagger}$, George M. Hornberger ${ }^{2}$ and Thushara Gunda ${ }^{3}$ \\ ${ }^{1}$ Department of Civil Engineering, Faculty of Engineering, University of Moratuwa, Katubedda, Moratuwa. \\ 2 Vanderbilt Institute for Energy and Environment, Department of Civil and Environmental Engineering, and Department of Earth and Environmental \\ Sciences, Vanderbilt University, USA. \\ ${ }^{3}$ Sandia National Laboratories, USA.
}

Revised: 6 May 2018; Accepted: 25 May 2018

\begin{abstract}
Impact of climate change on soil properties has been studied by several researchers. However, the influence of soil moisture has received little attention as a key component of agricultural climate change. Using meteorological data in Anuradhapura District in Sri Lanka (one of the main paddy producers in the island nation), this study evaluated the impact of climate change on soil moisture. Monthly soil moisture values were calculated using a water balance approach. Analysis of historical data (from 1950 to 2016) indicate a strong seasonal influence on soil moisture patterns. Correlation analysis between paddy yield and physical variables indicated that soil moisture is a stronger covariate than either temperature or precipitation alone. A good relationship between soil moisture and the El Niño effect was not identified. Scenario analyses indicated that soil moisture is more sensitive to precipitation changes than temperature changes in Anuradhapura. This study highlights the value of continuous monitoring of soil moisture along with other climatic data for insights regarding mitigation of future agricultural concerns.
\end{abstract}

Keywords: Climate change, meteorological data, paddy production, water balance, wavelets.

\section{INTRODUCTION}

Soil moisture has a direct impact on food security, human health and ecosystem functions. Several soil-forming processes, including organic matter turnover, structure formation, weathering, podsolization and gleying are strongly affected by soil moisture content (Karmakar et al., 2016). Soil moisture also plays a key role in providing resilience to climate change by buffering against extreme events, such as droughts and heat waves (McColl et al., 2017). Soil moisture serves to store water during periods of rainfall; the availability of this water to plants during dry periods helps buffer against climate variability and to increase the local area's resilience. Specifically, soil moisture content can influence crop yields and irrigation water requirements ( $\mathrm{Lal}, 1989)$.

Variations in air temperature and precipitation at event, seasonal, interannual, and decadal time scales will affect soil moisture. Precipitation affects water infiltration, water storage in the soil, surface runoff and erosion, ground water recharge, and evapotranspiration (Varallyay, 2010). Through surface radiation, heat conduction and convection processes, temperature has a strong influence on soil moisture content (Qian et al., 2011). Although organic matter alone has minimal impact on soil available water capacity (Minansy \& McBratney, 2017), the indirect effect of changing vegetation stress can affect transpiration and therefore soil moisture (Sprenger et al., 2017). In addition, local conditions of temperature, relative humidity, and wind speed all impact evapotranspiration, which in turn influences the soil moisture content. Thus, soil moisture plays a key role moderating feedback between local climate and soil processes.

\footnotetext{
*Corresponding author (udeni@uom.lk; (DD https://orcid.org/0000-0002-3472-6622)

$\dagger$ This study was conducted while on sabbatical leave at Vanderbilt University, USA.
} 
Climate change projections are generally less uncertain for temperature than for precipitation conditions, especially across different seasons. For example, in north central Sri Lanka, mid- $21^{\text {st }}$ century projections for temperature are consistently about $2{ }^{\circ} \mathrm{C}$ higher across seasons whereas the corresponding rainfall scenario varies from increased to decreased precipitation depending on the season (Zubair et al., 2015).

In this work, two questions about climate and soil moisture are addressed: 1) which climate conditions drive the variability in soil moisture? and 2) how do these conditions vary in time, across seasons? This analysis focused on understanding the relative influence of temperature versus precipitation on driving soil moisture patterns in Anuradhapura both historically and into the future. The historical analysis considers temporal variation of the primary variables of temperature and precipitation on soil moisture as well as regional climate phenomena such as El Niño, whereas the future analyses are scenario-based. These scenarios help to evaluate the sensitivity of soil moisture to different climate conditions. Climate change is expected to impact crop productivity (Kang et al., 2009). So given the prominent agricultural production in this region, the historical assessment also considers climate influences in paddy production. A water balance modelling approach is useful for addressing these questions. Qualitative comparison of the patterns of soil moisture derived from the water balance with those from satellite data indicates that this approach could be useful for assisting in decisions about seasonal crop water allocations as adaptations to climate change evolve.

\section{METHODOLOGY}

\section{Study site}

Anuradhapura is located in the Dry Zone according to the agro-ecological zones based on annual rainfall of 800 $-1200 \mathrm{~mm}$ year $^{-1}$. The Dry Zone predominantly receives rainfall during the Northeast Monsoon (December February) and inter-monsoon (October - November). Anuradhapura District is one of the key rice producing areas containing $10 \%$ of total paddy lands in the country (Gunarathna \& Kumari, 2013). However, recent droughts have raised concerns about the sustainability of paddy agriculture in the North Central Province, including the Anuradhapura District. Further, paddy cultivation is highly susceptible to changes in temperature and precipitation (De Silva et al., 2007).

\section{Water balance model and data}

A water balance approach is considered in this analysis using precipitation, temperature and other information about local conditions to evaluate soil moisture at a monthly time-step. The analysis considers antecedent conditions as well, notably the soil moisture at a given time-step. Given the complexity of these calculations, manual calculations of soil moisture using a water balance approach is quite time-consuming, so a MATLAB tool provided by Jacobi et al. (2013) (for calculating the Palmer drought severity index) is adapted in the analysis. This model requires monthly values of temperature and precipitation and specification of the soil available water content (AWC); evapotranspiration values were estimated using the Thornthwaite method (Thornthwaite, 1948). Monthly precipitation and temperature data for 1950 - 2016 were obtained from the Meteorological Department of Sri Lanka. Missing data were filled by using methods described by Gunda et al. (2016). AWC was estimated using the soil classification of Mapa et al. (2010), which is based on a few direct measurements extended using soil texture. The estimates showed good agreement with Keerthisena et al. (2001) for 9 soil samples collected near Anuradhapura (Figure 1). Soil classification, and therefore AWC, did not vary based on whether the area was in a rain-fed agricultural system or an irrigated system. Soil water content calculated using the water balance is the water available in the unsaturated zone and expressed as water depth in $\mathrm{mm}$ per $1 \mathrm{~m}$ of soil thickness. Thus, the calculated soil water values will vary between zero and the AWC. Soil moisture deficit (SMD) is defined as the difference between the AWC and the available moisture in the soil. Stable values were obtained from March 1951 to August 2015.

\section{Temporal patterns}

Soil moisture anomalies were calculated by subtracting the grand monthly mean of calculated values from the AWCs. To characterise temporal patterns in the anomalies, a continuous wavelet transform (CWT) was generated and dominant modes of variability were identified over time and frequency space; wavelet theory and background information is discussed by Torrence and Compo (1998), and Grinsted et al. (2004). Because the Niño 3.4 dataset explains some of the variability in agricultural production and drought in Sri Lanka (Gunda et al., 2016), a cross-wavelet transform (XWT) was used to assess the relationship between the monthly anomalies of soil moisture and Niño 3.4 temperatures. All wavelet 
analyses were conducted with a Bartlett window in $\mathrm{R}$ using the WaveletComp package. Patterns of seasonal moisture variation from the water balance were compared with soil moisture active passive (SMAP) satellite data available from April 2015.

\section{Impact of soil moisture on paddy yield}

Paddy yield data for the Anuradhapura District was collected from the Sri Lanka Statistics Department from 1979 to 2016. Rain-fed agriculture information is separately available only from 2005 onwards. Linear regression was used to understand the relationship between paddy yield and seasonal averages of soil moisture, temperature, and precipitation for Maha (October to February) and Yala (April to August) seasons. The coefficients of determination $\left(\mathrm{R}^{2}\right)$ for paddy yield with individual and combined independent parameters were studied to determine the overall relevance of soil moisture in influencing paddy yield in the Anuradhapura District.

\section{Scenario analysis}

Global warming projections indicate an increase in the air temperature of more than $1{ }^{\circ} \mathrm{C}$ while average rainfall pattern projections indicate a decrease between $9-17 \%$ in the island nation by mid-century (De Silva et al., 2007). Therefore, this study considered a future scenario of an increase in the temperature by $2{ }^{\circ} \mathrm{C}$ and a decrease of precipitation by $10 \%$. The available set of data from 1950 - 2016 was altered to reflect the climate change scenario, treating the conditions in a counterfactual approach. Specifically, elevated temperatures and reduced precipitation were introduced as a change in the historical monthly data from 1950 - 2016. To explore the sensitivity of soil moisture to different conditions of temperature and precipitation, intermediate scenarios, such as an increase in temperature alone by $1{ }^{\circ} \mathrm{C}$ and $2{ }^{0} \mathrm{C}$ without changing the precipitation, decrease in precipitation by $10 \%$ without altering temperature, and combinations of $1{ }^{\circ} \mathrm{C}$ and $2{ }^{\circ} \mathrm{C}$ increments with $10 \%$ decrease in precipitation, were also explored. Soil moisture values under these varying conditions were estimated using the water balance component of Jacobi et al. (2013)'s MATLAB tool aforementioned and the resulting changes were evaluated relative to historical conditions.

\section{RESULTS AND DISCUSSION}

Nine soil samples from six different locations were evaluated for clay, silt, sand, and gravel content (Figure 1).



Figure 1: Soil sampling locations in Anuradhapura District. 
Table 1: Soil texture and classification of nine soil samples in Anuradhapura. All percentages are based on weight.

\begin{tabular}{llccccl}
\hline Site & Description & Gravel $\%$ & Sand $\%$ & Silt $\%$ & Clay $\%$ & USDA classification \\
\hline 1 & Arunagama & 12 & 81 & 8 & 11 & Sandy loam \\
2 & Kahatagasdigiliya & 20 & 85 & 6 & 9 & Loamy sand \\
3 & Ranpathvila & 21 & 86 & 5 & 9 & Loamy sand \\
4 & Rambewa & 12 & 82 & 7 & 11 & Sandy loam \\
5 & Thalawa & 33 & 81 & 6 & 13 & Sandy loam \\
$6 \mathrm{~A}$ & Huruluweva-muddy & 2 & 95 & 1 & 4 & Sand \\
$6 \mathrm{~B}$ & Huruluweva-dry & 30 & 59 & 16 & 26 & Sandy clay loam \\
$6 \mathrm{C}$ & Huruluweva-chena & 4 & 63 & 12 & 25 & Sandy clay loam \\
6D & Huruluweva-forest & 8 & 65 & 24 & 11 & Sandy loam \\
\hline
\end{tabular}

Collected samples fall into Horizon $\mathrm{A}$ and $\mathrm{AB}$ in reddish brown earth (mature), whose parent materials are derived from gneisses of the khondalite series (Kalpage et al., 1963). The average AWC is $97.6 \mathrm{~mm}$ for this area or about $10 \%$ expressed as water per meter of soil well, an estimate that agrees with Mapa et al. (2010). The US Department of Agriculture (USDA) classifications of the soil samples, which are primarily sand-dominated, agreed with those reported by Keerthisena et al. (2001) (Table 1).

Soil moisture values estimated using these site characteristics indicate a strong seasonal trend. Notably, soil moisture deficits (SMD) are high between February and September, with an extended dry period from June - September when SMDs are near maximum values (Figure 2). Low SMD values during November and December indicate lower water stress during this time of the year (Figure 2). Soil moisture data from the SMAP satellite, that measures moisture content in top $5 \mathrm{~cm}$ of soil, shows a seasonal pattern that is in general agreement with the pattern from the water balance calculation, which measures moisture content for the surface layer of $1 \mathrm{~m}$ thickness (Figure 3). Both the water balance and SMAP show peaks in soil moisture in April - May and in October - December and valleys in June - August (Figures 2 and 3).

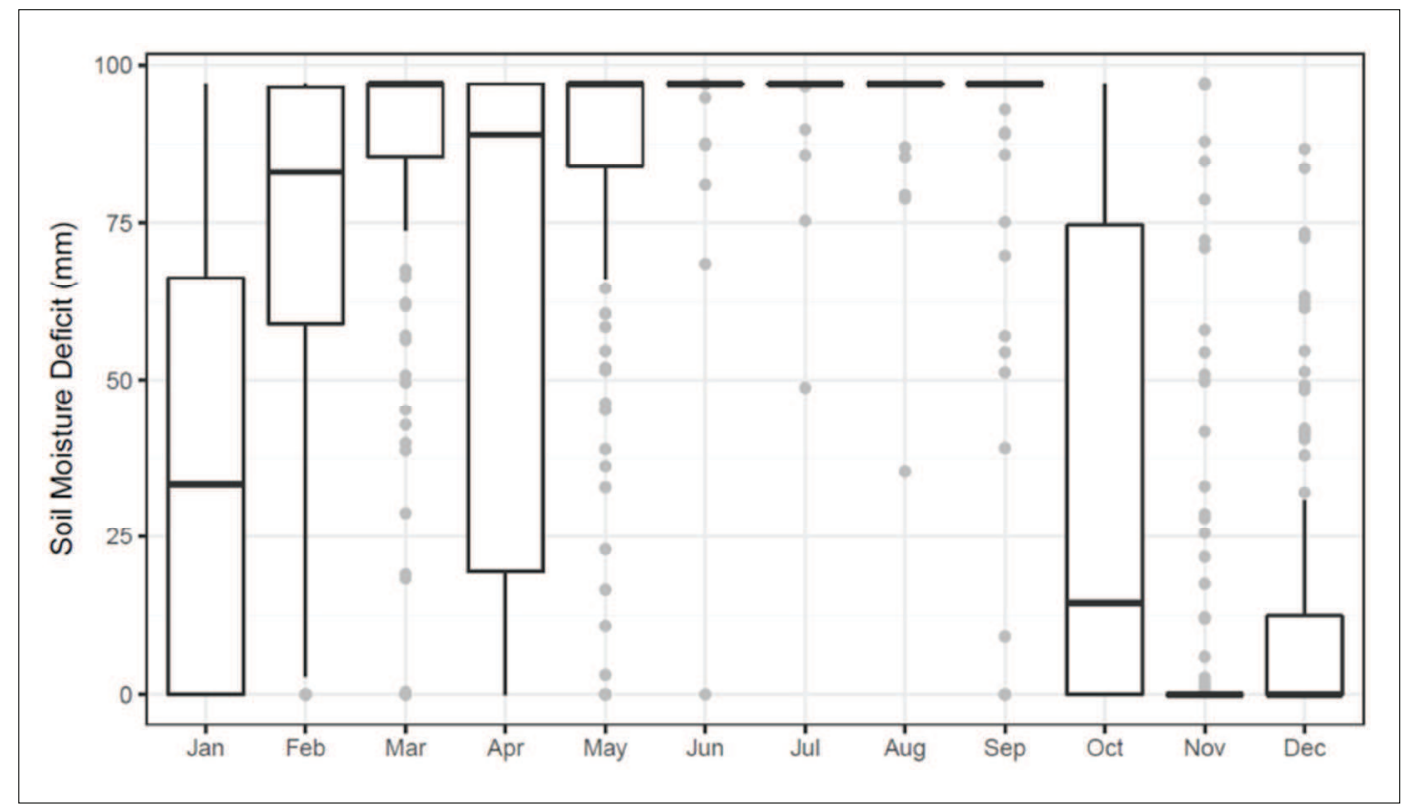

Figure 2: Monthly values of soil moisture deficit. The rectangles show the first to third quartile of the data for each month; the segment represents the median values while the lines indicate minimum and maximum values. 
The CWT for soil moisture does not show any dominant modes of variability over time or frequency space (Figure 4). Although the XWT of soil moisture and Niño data have regions with high power, there are no distinct time periods or frequencies during which the two datasets have a consistent phase relationship (Figure 5). Jayawardene et al. (2015) proposed a periodicity of 3.9 years for southern oscillation index (SOI) in Anuradhapura considering the results of the cross-spectral analysis between monthly precipitation and selected weather indices. However, the lack of consistent phase relationship between soil moisture and Niño data (Figures 4 and 5) indicates that no such relationship is present with soil moisture; the high power in the XWT is most likely driven by the high power in the CWT of the Niño dataset during the last few decades, the latter of which is shown by Gunda et al. (2016).

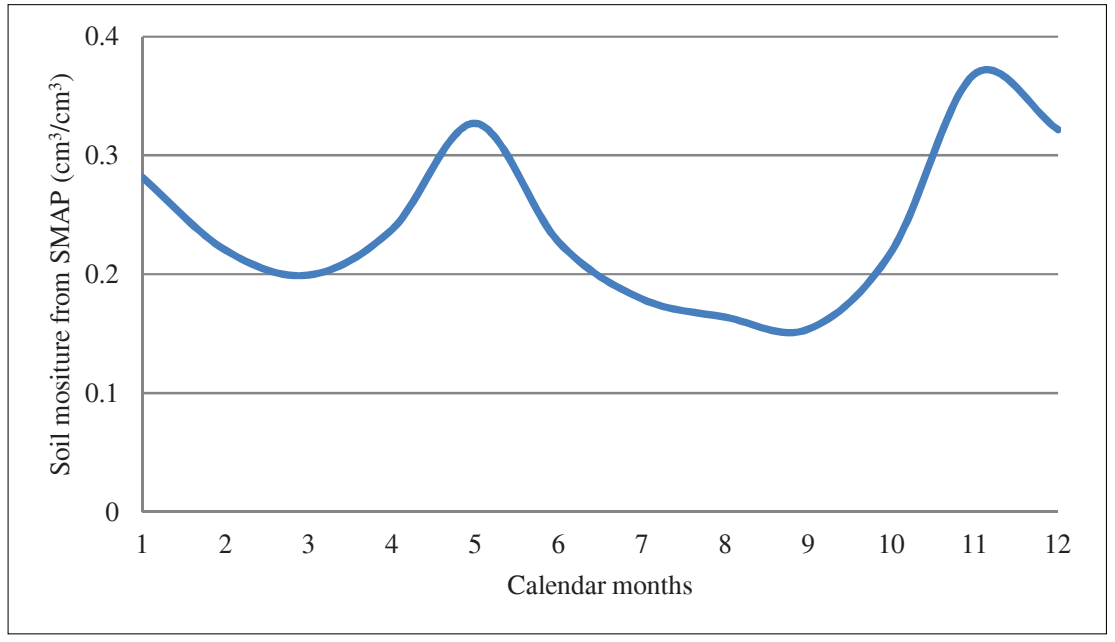

Figure 3: Soil moisture variation in Anuradhapura using SMAP satellite data

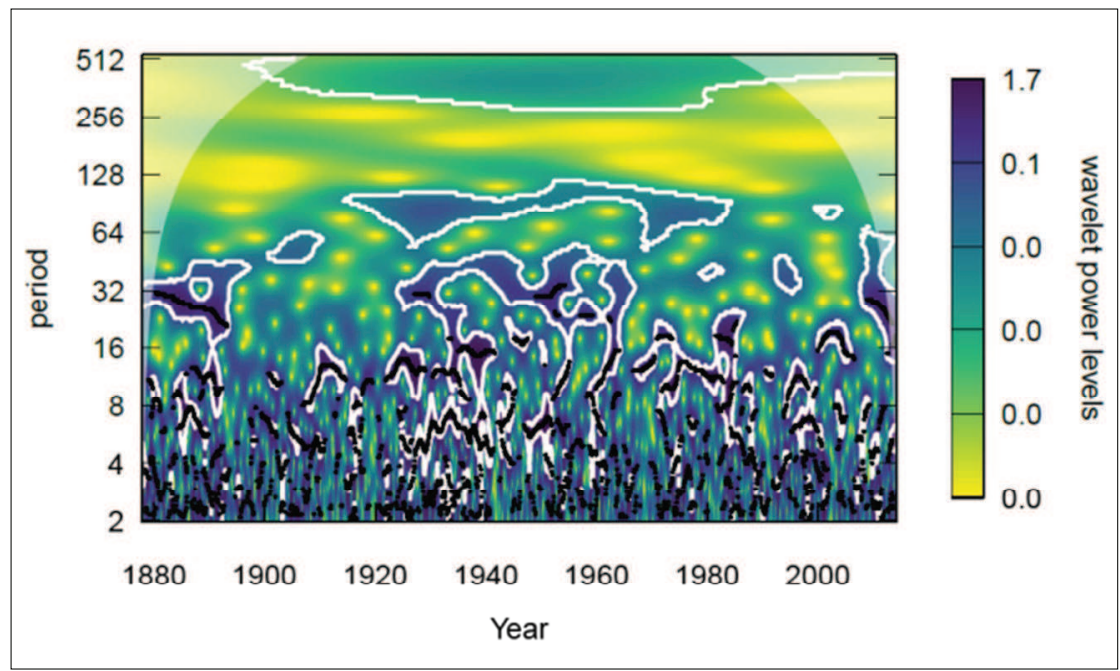

Figure 4: Continuous wavelet transform of soil moisture anomalies at Anuradhapura. The y-axis (period) is in units of months. The power of the wavelet is indicated by the strength of the shading, regions outside the cone of influence should be viewed with caution. No dominant modes of variability are apparent in the wavelet. 




Figure 5: Cross-wavelet transform of soil moisture and Niño 3.4 dataset anomalies at Anuradhapura. The y-axis (period) is in units of months. The power of the wavelet is indicated by the strength of the shading, regions outside the cone of influence should be viewed with caution. Although there are regions of high power between the two wavelets the orientation of the arrows indicates there are no distinct time periods or frequencies during which the two datasets have a consistent phase relationship.

Table 2: Summary of $\mathrm{R}^{2}$ values for both average and rain-fed agriculture systems in Anuradhapura

\begin{tabular}{lcccc}
\hline Variables influencing yield & \multicolumn{2}{c}{$\begin{array}{c}\mathrm{R}^{2} \text { of total yield } \\
(1979-2016)\end{array}$} & \multicolumn{2}{c}{$\begin{array}{c}\mathrm{R}^{2} \text { of Rain-fed yield } \\
(2005-2016)\end{array}$} \\
& Maha & Yala & Maha & Yala \\
\hline Temperature & 0.17 & 0.11 & 0.11 & 0.003 \\
Precipitation & 0.05 & 0.007 & 0.07 & 0.09 \\
Soil moisture & 0.22 & 0.07 & 0.25 & 0.15 \\
Temperature and precipitation & 0.22 & 011 & 0.26 & 0.11 \\
Temperature and soil moisture & 0.37 & 0.21 & 0.47 & 0.16 \\
Precipitation and soil water & 0.27 & 0.08 & 0.28 & 0.15 \\
Temperature, precipitation and soil moisture & 0.41 & 0.23 & 0.48 & 0.16 \\
\hline
\end{tabular}

As noted by Folberth et al. (2016), soil texture, interacting with changes in precipitation and plant water requirement, is an important consideration in climate change assessments. If precipitation decreases moderately, climate change can cause a more severe impact on crop yields in soils with lower water holding capacity that are drained rapidly, whereas a soil of finer texture may buffer the potential moisture deficit by storing water for longer periods. Given the sandy textures in the region, the soils in the Anuradhapura District are prone to rapid draining and could enhance water scarcity concerns for plants. A regression analysis of paddy yield for both total (irrigated and rain-fed) and rain-fed agriculture systems indicates the critical role of soil moisture in controlling rice production in Anuradhapura (Table 2). Regressions were performed using individual variables and combinations of variables. The strength of the association between independent variables and yield was assessed by considering the coefficient of determination $\left(\mathrm{R}^{2}\right)$, which is interpreted as the percentage of the variance in the dependent variable (yield) that is predictable from the independent variable(s). The coefficients of determination indicate that soil moisture explains more of the variability than 
temperature or precipitation alone in both Maha and Yala seasons (Table 2). In rain-fed agricultural regions, in particular, soil moisture and temperature explain as much variability as the combination of all three variables: soil moisture, temperature and precipitation (Table 2). These findings highlight the prominent influence of soil moisture on paddy yields in both seasons in this region of the country.

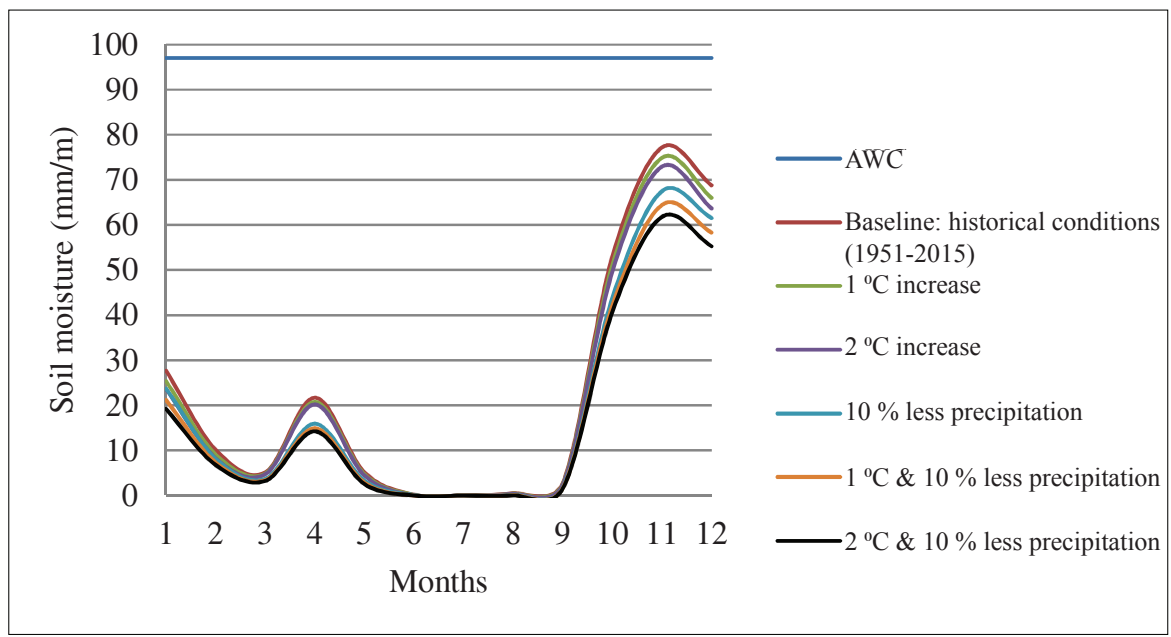

Figure 6: Soil water variation in different scenarios (1951 - 2015)

A comparison of average seasonal soil moisture between the baseline condition $(1951-2015)$ and likely scenarios of elevated temperatures and reduced precipitation indicate that climate change will have a pronounced impact on soil moisture (Figure 6). In particular, between the months of October and January, soil moisture could decrease by almost $20 \mathrm{~mm} / \mathrm{m}$ in the $2{ }^{\circ} \mathrm{C}$ and $10 \%$ lower precipitation scenario. Generally, impacts of precipitation on soil moisture are more pronounced than those of temperature alone (Figure 6). Overall, the decrease in soil moisture under climate change scenarios (Figure 6) indicates that the severity of dry soil periods is expected to increase in the future.

Storage of water in soils is an important buffering mechanism to protect plants from short-term periods of low rainfall. Thus, changes in soil moisture resulting from climate change pose a threat. The results show that a temperature increase of $2{ }^{\circ} \mathrm{C}$ and a decrease of precipitation by $10 \%$ would reduce soil moisture significantly, and potentially result in a significant impact on paddy yield. Monitoring of soil moisture along with other meteorological data would provide critical information for planning for adaptation to climate change. In particular, the water balance method could be combined with seasonal climate forecasts to calculate expected soil water deficits. The use of SMAP remote sensing data to periodically update the water balance calculations may be useful to forecast future drought situations. SMAP is available with daily data and further work may show that calculations of soil moisture on a daily basis may be useful.

\section{CONCLUSION}

This study confirms the adverse impacts of climate change on soil properties in the Anuradhapura District. Specifically, the combination of both high temperature and low precipitation would reduce the soil moisture. Given the high water scarcity conditions already experienced in the Yala season, the impact of these deficits would be particularly high. In Maha season, frequent replenishment of the soil profile by heavy rains could diminish climate change impacts on soil moisture content. It was further observed that soil moisture does not show a strong relationship with El Niño data.

Increases in temperature and reductions in precipitation will likely reduce soil moisture. Given the strong association between climate variables and paddy yield, soil moisture deficit along with elevated temperature and precipitation reductions could cause considerable stress on the paddy yield in Anuradhapura District. At present, traditional tank-based agriculture systems are not sufficient to cater the water demand in Anuradhapura and it is therefore vital to study the climatic changes and develop a crop plan, which can 
optimise the use of rainfall to reduce the irrigation water demand. Therefore, a critical need is to monitor the soil moisture changes along with other climatological data in agriculture-based districts like Anuradhapura.

\section{Acknowledgement}

This work was supported by the United States NSF grant numbers WSC-1204685 and DGE-0909667. The technical assistance provided by Sandia National Laboratories is acknowledged. Authors would also like to thank the National Building Research Organization (NBRO) for providing field support in Sri Lanka.

The views expressed in the article do not necessarily represent the views of the U.S. Department of Energy or the United States Government.

\section{REFERENCES}

De Silva C.S., Weatherhead E.K., Knox J.W. \& RodriguezDiaz J.A. (2007). Predicting the impacts of climate change - a case study of paddy irrigation water in Sri Lanka. Agricultural Water Management 93(2007): 19 - 29. DOI: https://doi.org/10.1016/j.agwat.2007.06.003

Folberth C., Skalsky R., Moltchanova E., Balkovic J., Azevedo L.B., Obsersteiner M. \& van der Velde M. (2015). Uncertainty in soil data can outweigh climate impact signals in global crop yield simulations. Nature Communications 7: Article number 11872.

DOI: https://doi.org/10.1038/ncomms11872

Grinsted A., Moore J.C. \& Jevrejeva S. (2004). Application of the cross wavelet transform and wavelet coherence to geophysical time series. Nonlinear Processes in Geophysics 11: $561-566$.

DOI: https://doi.org/10.5194/npg-11-561-2004

Gunarathna M.H.J.P. \& Kumari M.K.N. (2013). Rainfall trends in Anuradhapura: rainfall analysis for agricultural planning. Rajarata University Journal 1: 38 - 44.

Gunda T., Hornberger G.M. \& Gilligan J.M. (2016). Spatiotemporal patterns of meteorological drought in Sri Lanka from 1880 - 2010. International Journal of Climatology 36: 563 - 575. DOI: https://doi.org/10.1002/joc.4365

Jacobi J., Perrone D., Duncan L.L. \& Hornberger G. (2013). A tool for calculating the Palmer drought indices. Water Resources Research 49: 6086 - 6089.

DOI: https://doi.org/10.1002/wrcr.20342

Jayawardene H.K.W.I., Jayawardene D.R. \& Sonnadara D.U.J. (2015). Interannual variability of precipitation in Sri Lanka. Journal of the National Science Foundation of Sri Lanka 43(1): 75 - 82.

DOI: https://doi.org/10.4038/jnsfsr.v43i1.7917
Kalpage F.S.C.P, Mitchell B.D. \& Mitchell W.A. (1963). The Mineralogy of Some Ceylon Soils. The Macaulay Institute for Soil Research.

Kang Y., Khan S. \& Ma X. (2009). Climate change impacts on crop yield, crop water productivity and food security - a review. Progress in Natural Science 19(12): 1665 - 1674. DOI: https://doi.org/10.1016/j.pnsc.2009.08.001

Karmakar R., Das I., Dutta D. \& Rakshit A. (2016). Potential effects of climate change on soil properties: a review. Science International 4: 51 - 73 .

DOI: https://doi.org/10.17311/sciintl.2016.51.73

Keerthisena R.S.K., Mapa R.B. \& Yapa P.A.J. (2001). Soil water dynamics in alley cropping systems in the dry zone of Sri Lanka. Tropical Agricultural Research 13: 123 - 133.

Lal R. (1989). Agroforestry systems and soil surface management of a tropical alfisol: I: soil moisture and crop yields. Agroforestry Systems 8(1): 7 - 29. DOI: https://doi.org/10.1007/BF00159066

Mapa R.B., Somasiri S. \& Dassanayake A.R. (2010). Soils of the Dry Zone of Sri Lanka. Special Publication No. 9, Soil Science Society of Sri Lanka. Suvodaya Vishwa Lecka Publishers.

McColl K.A., Alemohammad S.H., Akbar R., Konings A.G., Yueh S. \& Entekhabi D. (2017). The global distribution and dynamics of surface soil moisture. Nature Geoscience 10: $100-104$.

DOI: https://doi.org/10.1038/ngeo2868

Minansy B. \& McBratney A.B. (2017). Limited effect of organic matter on soil available water capacity. European Journal of Soil Science 69: 39 - 47.

DOI: https://doi.org/10.1111/ejss.12475

Qian B., Gregorich E.G., Gameda S., Hopkins D.W. \& Wang X.L. (2011). Observed soil temperature trends associated with climate change in Canada. Journal of Geophysical Research 116(D2).

DOI: https://doi.org/10.1029/2010JD015012

Sprenger M., Tetzlaff D. \& Soulsby C. (2017). Soil water stable isotopes reveal evaporation dynamics at the soil-plantatmosphere interface of the critical zone. Hydrology and Earth System Sciences 21: 3839 - 3858.

DOI: https://doi.org/10.5194/hess-21-3839-2017

Thornthwaite C.W. (1948). An approach toward a rational classification of climate. Geographical Review 38: 55 - 94. DOI: https://doi.org/10.2307/210739

Torrence C. \& Compo G.P. (1998). A practical guide to wavelet analysis. Bulletin of the American Meteorological Society 79(1): $61-78$.

Varallyay G. (2010). The impact of climate change on soils and their water management. Agronomy Research 8: 385 - 396.

Zubair L. et al. (24 authors) (2015). Climate Change Impacts on Rice Farming Systems in Northwestern Sri Lanka. Handbook of Climate Change and Agroecosystems ICP Series on Climate Change Impacts, Adaptation and Mitigation, pp. 315 - 352. World Scientific Publishing Co., Inc., USA.

DOI: https://doi.org/10.1142/9781783265640_0022 